\title{
TOOTH MOBILITY MEASUREMENTS- REALITIES AND LIMITATIONS
}

\author{
Karthikeyan Bangalore Varadhan'1, Shagufta Parween², Aditi Ketan Bhavsar ${ }^{3}$, Munivenkatappa Lakshmaiah Venkatesh Prabhuji ${ }^{4}$
}

1Professor, Department of Periodontology, Krishnadevaraya College of Dental Sciences, Bengaluru, Karnataka, India.

2Postgraduate Student, Department of Periodontology, Krishnadevaraya College of Dental Sciences, Bengaluru, Karnataka, India.

3 Postgraduate Student, Department of Periodontology, Krishnadevaraya College of Dental Sciences, Bengaluru, Karnataka, India. 4 Professor and HOD, Department of Periodontology, Krishnadevaraya College of Dental Sciences, Bengaluru, Karnataka, India.

\section{ABSTRACT}

\section{BACKGROUND}

Tooth mobility is a common sequel as well as possible aggravating co-factor for periodontal disease. Its effective management has a profound influence on the outcome of periodontal therapy. For the efficient clinical management of tooth mobility, it is necessary to have a reliable diagnostic tool that can accurately measure and quantify the mobility. This article addresses the various diagnostic methods available and assesses their limitations. Further, it also highlights some new frontiers in the field of mobility diagnosis and measurements.

\section{KEY WORDS}

Tooth Mobility, Measurements, Instruments, Indices, Periodontal Disease

HOW TO CITE THIS ARTICLE: Varadhan KB, Parween S, Bhavsar AK, et al. Tooth mobility measurements- realities and limitations. J. Evolution Med. Dent. Sci. 2019;8(16):1342-1350, DOI: 10.14260/jemds/2019/298

\section{BACKGROUND}

Tooth mobility has enthralled the interest of investigators for practical and scientific accounts.[1] Teeth display a certain degree of mobility as they are suspended in the jaw bone by a network of collagenous fibers and are not ankylotically anchored. To differentiate between physiological and pathological tooth mobility, the magnitude of amplitude of crown displacement has then been used.[2]

Diseases of the tooth-supporting structures necessarily influence the solidness of anchorage or the grade of toothmobility. Increased mobility or loosening of teeth is a chief symptom which is used to evaluate the status of the periodontium and success or failure of periodontal treatment. The extent of periodontal disease cannot be correctly appraised without evaluating the degree of mobility.[3] The clinical method of determining tooth mobility relies on individual's perception of tooth movement on application of force to the tooth.[4] It is not precise, and is subject to prejudice because of the perspicacity of the examiner and its accurate measurement is indispensable.

Thus, there is a need of a punctilious and equitable technique having diverse functional usage. There are presently various traditional diagnostic tools to detect and evaluate the extent of the disease. However, inherent limitations exist in determining accurate measurements due to various factors such as the anatomy, the need for the sound technical skills and compliance of the patient. Because of these factors there is always a quest for newer diagnostic tools and modern treatment modalities for accurate mobility diagnosis and treatment.

'Financial or Other Competing Interest': None.

Submission 25-02-2019, Peer Review 05-04-2019,

Acceptance 11-04-2019, Published 22-04-2019.

Corresponding Author:

Dr. Karthikeyan Bangalore Varadhan,

Krishnadevaraya College of Dental Sciences,

Krishnadevaraya Nagar, Hunasamaranahalli,

International Airport Road,

Bangalore-562157,

Karnataka, India

E-mail: periokcds@gmail.com

DOI: $10.14260 /$ jemds $/ 2019 / 298$
The objective of this review is to bring the reader up-todate on the realities and limitations of the various traditional and current methods used for the diagnosis of tooth mobility and, in addition, the various advanced methods in tooth mobility measurements are briefly discussed.

\section{Call for Accurate Tooth Mobility Measurement}

Tooth mobility measurements enable an objective assessment of the outcomes of various therapeutic procedures. In the overall evaluation of patient's, tooth mobility accounts for just one small part, notable importance is put upon quantification of mobility during both periodontal diagnostic scrutiny and as alterations occurs amid successive re-evaluations. ${ }^{[5]}$ Often patients correlate the changes in mobility before and after the periodontal therapy as the only criterion for success of the therapy. This highlights the great need for accurate mobility measurements, which can be summarized as follows-

1. An immediate relation exists between increasing mobility and a deteriorating prognosis.

2. Tooth mobility is an extremely useful clinical indicator of the biophysical state of connective tissue and bony tooth supporting structures. In elderly patients along with subgingival plaque microorganism, tooth mobility is the best predictor of alveolar bone loss.[6]

3. Teeth with increased mobility present with an increased possibility for attachment loss either in short term and in a long term than non-mobile teeth.[7]

\section{Limitations in Tooth Mobility Measurements Influence of Anatomy}

The degree of tooth mobility is dependent on quantitative factors (Surface area of periodontal ligament attachment) and qualitative factors (Biophysical properties of the periodontium). Expression of so- called normal tooth mobility even after standardization of loading forces cannot be done by one single value.[8] Physiologic or normal tooth mobility is dependent on (i) the quality or visco-elastic properties of the periodontal tissue and on (ii) the anatomical characteristics such as the amount of supporting alveolar bone and the width of the periodontal ligament space. Other factors such as number, shape and length of the roots or the 
intrinsic elasticity of the tooth itself may also be considered.[9] These properties lead to difficulties in the evaluation of the periodontal tissue condition including tooth mobility, since the elastic and viscous properties are responsible for the nonlinear and time-dependent behaviour of the periodontal ligament

\section{Influence of Investigator Experience}

Subjective methods where the tooth is deflected between two instrument handles are widely accepted in the clinical routine, but are operator-dependent and non-reproducible. Investigator experience in measuring tooth mobility influences the accuracy and reproducibility of the diagnostic performance. Periodontists were not in agreement when comparing teeth with the Miller Index across distinct subjects as deduced by Laster et al. (1975).[10]

\section{Influence of Cardinal Variations}

Tooth mobility is dynamic: mainly due to functional and biological influences as diurnal variation is seen in single teeth and the same individual.[7] It is more marked in the young compared to healthy adult dentition; it increases during periodontitis during an apical abscess and during orthodontic treatment. Mobility is higher during pregnancy, though, physiological qualitative changes alone may occur during pregnancy.[1] Unilateral functioning of the dentition for longer period of time demonstrates higher mobility on the hypofunctional side than the juxtaposed side.

\section{Influence of Diagnostic Methods}

Increase in tooth mobility can be a result of various physiological or pathological factors. Pathological mobility is caused by injury to the periodontal structures. Pathological mobility occurs due to quantitative and/ or qualitative alterations of the tooth supporting structures. Tooth mobility occurs in two stages - initial/ intra socket stage and secondary stage. Initial/ Intra socket stage occurs within confines of the periodontal ligament. It occurs due to viscoelastic distortion of periodontal fluid, periodontal fibres and inter bundle content. The movement ranges from 50-100 $\mu \mathrm{m}$, under a load of $100 \mathrm{lb}$. Secondary stage occurs due to elastic deformation of alveolar bone in reaction to increased horizontal forces.[7]

A wide number and diversity of methods to measure tooth mobility have been reported due to which the investigator faces a complicated problem of assessing the degree of tooth mobility. For comprehensive evaluation tooth mobility, three-dimensional measurements are required. Such measurements are probably complex for practical motives. Most investigators have enclosed tooth mobility studies in single direction, either the bucco-lingual or the axial.[11] Different methods, which vary in rate, frequency, time span and amount of applied force, do not necessarily represent the same properties of the periodontium. Plethora of methods and devices are available for the veracious assessment of mobility. These can be categorized under the following headings:

\section{Clinical Methods}

These methods are widely used in routine clinical practice to assess tooth mobility and are subjective in approach. These includes: Direct visualization when tooth is held between two rigid instruments/finger and direct observation of movement resulting from occlusal forces. Current mobility grading systems are applicable in assessing severity of mobility when diagnosing initial or maintenance cases, but these systems rely solely upon direct measurements to assess severity, however, do not address causative factors. These methods are non-scientific, insufficient and do not ascertain mobility objectively as it is influenced by the clinician's tactile perception, hence subjected to individual interpretation. The linear measurement ascertained by these methods quantifies movement, but does not address aetiology.[5] Figure 1., Table 1.

\section{Electronic Devices}

For a more scientific and objective evaluation of degree of tooth mobility, various electronic devices have evolved over the past years as they deliver accurate with reproducible values. The devices present till date are briefly discussed below:

\section{Elbrecht's Indicator (1939)}

This was the first device designed for the objective measurement of tooth mobility by Elbrecht in the year 1939. This device measures tooth mobility with a large dial indicator which registers the labio-lingual crown excursions produced by digital pressure. The dial indicator is secured on a tripod in front of the patient's mouth. This method of measurement is unreliable as the motions of the head could interfere with the movements of the crowns giving inaccurate values. It measures only values above $0.75 \mathrm{~mm}$ in total labiolingual crown excursions. ${ }^{[12]}$ Further, these procedures were problematic since considerable forces were required to cause shift of a thousandths of inch.[4]

\section{Werner's Oscillator (1942)}

It is a more complex oscillometer designed by Werner in 1942. The equipment is clutched and attached on the anterior teeth consisting of a rod with a scale. A force of 700 grams is applied by moving the neighbouring or adjacent tooth labiolingually and the resultant disagreement of tooth position is recorded on the scale. However, this method could not assess differences of tooth position lesser than $0.25 \mathrm{~mm} .{ }^{[12]}$

\section{Beyeler and Dreyfus Vibrator $(1947,1949)$}

Elbrecht and Werner were able to register only gross differences in tooth mobility with their measuring devices. Employing a similar technique, Beyeler and Dreyfus measured tooth mobility by subjecting teeth to oscillatory vibrations of high frequency. This device measured behaviour of teeth on subjecting to high frequencies. The vibrometer uses oscillatory vibrations to determine the behaviour of teeth instead of labiolingual excursions of crowns. [12] The device does not report tooth mobility but instead measures the elasticity of the root's suspensory apparatus. No clinical studies were reported using this device.[12]

\section{Manly's Mobilometer (1951)}

Manly used similar vibration technique as Beyeler and Dreyfus vibrator, however, with higher and variable frequencies. [13] Vibration technique would possess advantages. By driving with a vibrating rod, the tooth is vibrated, the mobility relates to the amplitude of vibration 
keeping the force constant. Employing this equipment, frequencies in the range of 20 to approximately 15, 000 cycles per second the rod could be set into longitudinal. The decibel meter determines the amplitude of the rod's vibration. The hand-piece consists essentially of a driving crystal, a vibration sensor and a coupling rod. These elements are encased in an aluminium frame. The incisal edge of the tooth hooks the coupling rod and along the long axis of the tooth the handle of the instrument is oriented. With least possible hand pressure the device is steadied in position and a foot switch is pressed. The foot switch is set free after the recording of the results. The degree of vibration can be estimated in terms of the voltage produced from a vibration pick up. The introduction of an instrument suitable for clinical trial required elimination of pressure sensitivity which was inherent in their previous model and this device which reported inconsistent results.[4]

\section{Zwirner's Oscillograph (1949-1952)}

Zwirner used cathode beam oscillograph to assess mobility of tooth on rats. He employed an electronic apparatus to study the axial tooth mobility by using the movable plates of a condenser. One of the plates is attached to the tooth to be measured and the other one to the substance in which the jaws of a rat are embedded. However, intricate design of the apparatus prevented practical applicability as it was incapable of producing results on humans. The technical difficulties encountered led to the lack of reports on humans.[14]

\section{Mühlemann's Periodontometer (1954)}

To overcome the drawbacks of previous mobilometers, two measuring devices originated by Muhlemann which have been popular and employed in various investigations.

\section{Mühlemann's Macro-Periodontometer}

The macro-periodontometer consists of an impression tray secured with a dial indicator and the point of the indicator being at right angles to the labial/ buccal surface being measured. The dynamometer deflects the teeth palatally or labially with a known force and this deflection is measured in hundredths of millimetres. Although the reproducibility of measurements is high, the usefulness of the instrument is limited, due to its design which primarily can be used only in the upper incisor, cuspid, and first premolar regions.[15]

\section{Mühlemann's Micro-Periodontometer (1954)}

The micro-periodontometer, on the other hand, had rubber dam clamp held to tooth on the contra lateral side of arch holding the small - dial indicator. Muhlemann states that precise use of the instrument is tough to learn, secondly, the technique is tedious, and values obtained are less duplicatable compared to macroperiodontometer.[12,15]

\section{Picton's Gauge (1957)}

Picton demonstrated axial tooth mobility relative to its neighbours by utilising resistance wire strain gauges. One end of the gauge is attached to a single tooth and the other to the adjacent teeth through a spring. A fine wire detected vertical movements of teeth The strain change was measured in a Wheatstone bridge circuit. Any change in the position of the test tooth relative to the adjacent teeth is detected by the two strain gauges. Measurement of each tooth requires insertion of a custom assembly on the tooth and another in the opposing arch. Thus, the complexity of this instrument prohibited its use in clinical trials. $[14,16]$

\section{Parfitt's Transformer (1958)}

This machine employs rectilinear transducers and is able of determining axial tooth movements using the neighbouring tooth as the reference point, simultaneously, the force applied to the tooth. With the help of impression compound, the instrument is secured to the posterior teeth. Both systems utilized transducers and test output can be registered on direct current meters, strip chart recorders or X-Y recording force and movement. A precision of $0.001 \mathrm{~mm}$. $\pm 7 \%$ axial tooth movements could be assessed with the machine. It also records the time of displacement and of recovery of position of the tooth when force is removed or varied. However, the narrated electronic apparatus is complex and the required time for obtaining measurements makes the instrument unsuitable for clinical trials.[17]

\section{Joel's Technique (1958)}

Joel (1958) devised a technique in which a mirror is attached to the tooth and the tooth deflection is demonstrated by the image formed on the contrary wall due to reflection. In some distance from the tooth one more mirror is attached, the measurement is reported to be accurate in case stationary reflected image is obtained. In spite, the technique could not record the values of the amount of movement of the tooth.[14,18]

\section{Goldberg's Periodontometer (1961)}

A periodontometer in which mobility of upper and lower teeth could be quantified at once was devised by Goldberg. It consists of a carrier device which is fixed in the oral cavity with cold cure acrylic or impression plaster by engaging the masticatory surfaces of both jaws. The carriage device is used with measuring devices or along with Mühlemann's periodontometry dial indicator. The carriage is guided around the mouth by a semicircular platform hooked to the acrylic occlusal keys and the device was only capable of horizontal anterior teeth measurement.[14,19]

\section{Korber's Transducer $(1963,1970)$}

Korber and Korber (1963) and Korber K. H. (1970) demonstrated a system that employs electronic transducers of an inductive non-contact design. It enables tooth movement analysis without bodily contacting the test tooth. It was reported that this system could detect, and record extremely small movements and it is impractical for clinical trials due to its complexity.[20,21]

\section{USAFSAM Periodontometer (1963)}

O'Leary and Rudd's approach for measuring tooth mobility comprised of $180^{\circ}$ rotatable recording point in a horizontal plane. Their periodontometer was designed to assess mobility of all teeth in both arches through second molar. The dial indicator readings were as precise as $0.001 \mathrm{inch}$. The instrument was attached and held on the arches with the support of clutch with an extra-oral female receptor. The average of the two measurements gives the mobility of the particular tooth. A modified force-meter was used for 
transmission of force to the teeth. The angle of application of force had to be controlled. Reproducibility was at the least equal to that obtained with the macro periodontometer. Despite, forces maintained upon the tooth for a greater time period could result in a progressive increase in the mobility interpretation and its use was limited only on the maxillary incisor teeth.[14,15]

\section{Pameijer's (1973)}

Pameijer (1973) designed a device which consists of a semiconductor strain gauge constructed into a removable appliance and incorporated as an element of a Wheatstone bridge. Bending of the strain gauge produces a voltage change which is amplified before feeding in the recorder. The patient's mouth only engages the starin gauge and its mounting. The aforementioned system allowed straight recordings during all measurements. A more accurate measurement in $1 / 1000$ of a millimetre was made possible with this simple device. Further, additional strain gauges can be used to measure n number of teeth at once.[14]

\section{Ryden's Laser Reflexion Method (1975)}

In this laser reflexion method, a high accuracy direct contactless measuring technique was employed for clinical purposes. Illuminating using laser beam on a patient's tooth attached to the equipment with the help of impression plate, a prototype has been tested. Using a coordinate system and photographic record, the reflected patterns were projected onto a screen. The calculation of tooth movement were done geometrically It permits the measurement of tooth mobility at a very short intervals. The establishment of fulcrum of the tooth was necessary for recording small variations at every recording of the movement. The reactions of the periodontal tissues being variable may affect the position of the fulcrum.[22]

\section{Dental Holographic Interferometry (1975)}

It is a non-contact and non-destructive method which uses a Q-switched double-pulsed ruby laser. In this method, a pulse length of $\mathrm{f} n \mathrm{n}$ is combined with an electronic sub miniature force sensor for pulse triggering that is initiated by the masticatory force of the patient. An oscilloscope registers force increase and pulse positions synchronously on the screen. The applied force exerted by the patient's masticatory muscles could then be elucidated according to its point of application, amplitude, duration and direction. A double exposed, synchronized hologram measures the corresponding surface deformation. This technique imparts ample and detailed information as its documentation is enhanced by means of a special photographic method.[23]

\section{Persson and Svensson Loading/Sensing Devices (1980)}

Persson and Svensson introduced an apparatus which recorded tooth mobility at forces under $100 \mathrm{p}$ bucco-lingually directed. For the sensing of force and displacement, strain gauges and a differential transformer were employed. The displacement is recorded at the same location and direction as the loading force. Two-channel potentiometric recorder acquires the documentation of signals. Application of small forces is an advantage of this device and the synchronous recording at same direction of force and displacement.[11]

\section{Kaneko's Non-Invasive Test (1986)}

A non-invasive test method proposed for testing the integrity of the implant tissue interface has been described by Kaneko. He described a simple technique for an in vivo assessment of the interfacial rigidity between a dental root implant and the surrounding bone. A small pulsed force is utilized to estimate the frequency and amplitude of the vibration of the implant. Force application to the implant and detection of the vibration signal from the implant are achieved by lightly touching it with two fine needles connected with piezoelectric elements.[24]

\section{Periotest (1992)}

A more popular method for determining tooth mobility was presented by Schulte 1987 and Schulte et al 1992 when the Periotest system was introduced. The value of 'periotest' depended mainly on the damping characteristics of the periodontium. An electromagnetically driven, electronically controlled tapping head is decelerated when it hits the tooth. The greater the stability of the periodontium, the higher is the damping effect and the faster the deceleration. It measured the amplitude of displacement of the teeth on impact loading but was inadequate to provide a complete overview of the overall periodontal status. Positioning of the device had to be horizontal on the tooth surface for application of impact load which is difficult. Physical injury was afflicted to the tooth due to strong impulsive force and was associated with pain and discomfort.[25] Figure 2.

\section{Resonance Frequency Analysis (1994)}

A test to assess implant stability by measuring the frequency of implant oscillation inside the bone was first demonstrated by Meredith in 1994.[26] A transducer is attached either directly to an implanted fixture or via a transmucosal abutment using a screw. The transducer comprises a small beam attached to two piezo-ceramic elements which is then vibrated by exciting one of the piezo elements with a sinusoidal. The response is measured by the second element. The first flexural (Bending) resonance frequency of the resulting system is observed. It is the transducer which vibrates and not the implant. There are diverse generations of transducers and assessment instruments. First generation transducers were represented by an L-shaped metallic accessory made of surgical stainless steel or titanium that was connected to the implant or the pillar. Alternatively, the latter ceramic piece measured the response to vibration and the signal was amplified by means of a frequency analyser prior to comparison with the original signal. Third generation instruments do not require computer to complete analysis, are small, light, easy and quick to use in routine clinic practice. This device allows non-invasive, objective evaluation of implant stability as opposed to most tests that render subjective results. The only operator variable which may influence the resonance frequency is the tightness with which the transducer is attached to the implant.[27] However, it is inappropriate to examine the status of periodontal tissues using only the resonance frequency.

\section{Laser Vibrometry (1998)}

This technique basis is evaluation of the mobility degree through dynamic analysis having recourse to the application 
of an impulsive excitation on the tooth by means of an impact hammer and the measurement of the displacement by a laser Doppler vibrometer. This arrangement facilitates uncomplicated and versatile noncontact measurements with precision and sensitivity $(<0.1 \mathrm{~mm} / \mathrm{s})$. With this current technique, it will be feasible to measure a pathological mobility of the tooth, before the manual technique can put in evidence an increase in teeth mobility.[28]

\section{Dental Implant Movement Checker for Dental Implant Mobility Assessment (Wijaya 2004)}

Dental implant movement (IM) checker was developed to quantify dental implant mobility. The prototype of the instrument is based on the tooth mobility tester, formerly developed by Wijaya. It was designed to overcome limitations of previous devices, such as restriction of measuring orientation, large size of the measuring probe, long measuring time and high impact force. The IM checker comprises of a newly developed measuring probe whose size is that of a typical dental drill to facilitate measurements at all regions of dental implants. A bimorph ceramics transducer is attached to the probe to actuate an implant at constant frequency and force amplitude and to detect acceleration response. Further, the bimorph ceramics are secured with a set of strain gauges for detecting preload during measurement. Measurement artefacts (Mainly due to probe handling) could be eliminated with new digital data acquisition system. It was possible to discriminate the artificial dental implant models in the range of clinical tooth mobility M0 with variation less than $6 \%$. The measuring time needed by five operators was less than $15 \mathrm{~s}$. Consequently, the IM checker has adequate measuring reliability and thus it could be introduced in dental practice. [29]

\section{No Contact Vibration Device (2008)}

This is an electromagnetic vibrating device utilizing an alternating sine wave for force generation without contact to vibrate the tooth was developed. An in vitro study was conducted by Yamane et al. in 2008 suggested that the experimental device was comprised of 3 elements: the vibrator; the detector; and the analyser. Using an electromagnetic vibration device and the frequency response characteristics derived from tooth vibration, the mechanical parameters resonant frequency, elastic modulus and coefficient of viscosity were calculated.

Compared to the contact vibration system, this electromagnetic vibration system was more exact. Moreover, the mechanical parameters could impart an unbiased appraisal of various periodontal tissue conditions.

As the metal rod is not movable, this apparatus becomes more compact. The setting of the device is uncomplicated rendering it easier to target the teeth in the oral cavity irrespective of other organs (e.g. tongue and cheeks). However, maintenance of consistency during practical application is the improvement required for this device. For maintaining the accurate distance from and angle to the tooth, hand-piece positioning holder, an angled hand-piece or a wireless acceleration sensor might be valuable.[30] Figure 3.

\section{Zwick Method (2011)}

An artificial model as described by Berthold et al was used. It consisted of a round aluminium base with six alveolar sockets which are arranged in a half round arc to simulate an almost a natural shape of dental arch. The two middle sockets were enlarged close to the clinical situation of injured loose teeth to allow increased tooth mobility. The root and the crown section of the stimulation teeth were made of stainless steel. The periodontal ligament for the uninjured teeth was made with silicon while that of the injured teeth with silicon and rubber foam. Apical screws were used for fine adjustment of tooth mobility. Tooth mobility was measured in the horizontal and then in the vertical dimension with the universal testing machine Zwick value. A continuous load of 0-10 $\mathrm{N}$ was used. The Zwick method offers quantitative metric information about tooth mobility. However, it is not feasible to convert vertical into horizontal values.[31]

\section{Konermann's Novel Intraoral Measuring Device (2016)}

This in vivo pristine device measuring tooth mobility elicited high accuracy and validity in practical use. Precision regarding the fine grading of the deflection durations demonstrated the performance of tooth displacement. The measurement curves precisely revealed the behaviour of loaded teeth Furthermore, the device for in vivo use was uncomplicated to handle. However, measurement results were impacted by the unwanted movements by the patient and the splint adaption by the investigator. ${ }^{[32]}$

\section{NEVD- Non-Contact Electromagnetic Vibration Device (2016)}

This device was evolved to objectively and accurately assess the overall periodontal tissue condition. This device analyses both tooth mobility as well as condition of periodontal tissue condition by using mechanical parameters, i.e., resonant frequency, elastic modulus, coefficient of viscosity by quantifying the vibration of the tooth using an electromagnetic force a displacement sensor can measure the distance to the target object and there are two types of sensors: contact type and noncontact type. One of the noncontact type is a laser displacement sensor which can measure the distance as well as the acceleration the target object without mechanical contact. One of advantages of the laser displacement sensor is that it can gauge vibration of the target object in the absence of an accelerometer. The connection of the accelerometer intensifies the entire mass of the simulated tooth. Using laser displacement sensor with this device could also provide better clinical operability by eliminating the attachment of an accelerometer that is connect to the fast Fourier transformation analyser by the cord.[33]

These methods are either tedious, complex and/or exorbitant for routine clinical application. The investigator requires training for the reproducibility of the results. They are high cost and require complicated apparatus, onedimensional recording. Further, there is limitation involved in direction of force application. 

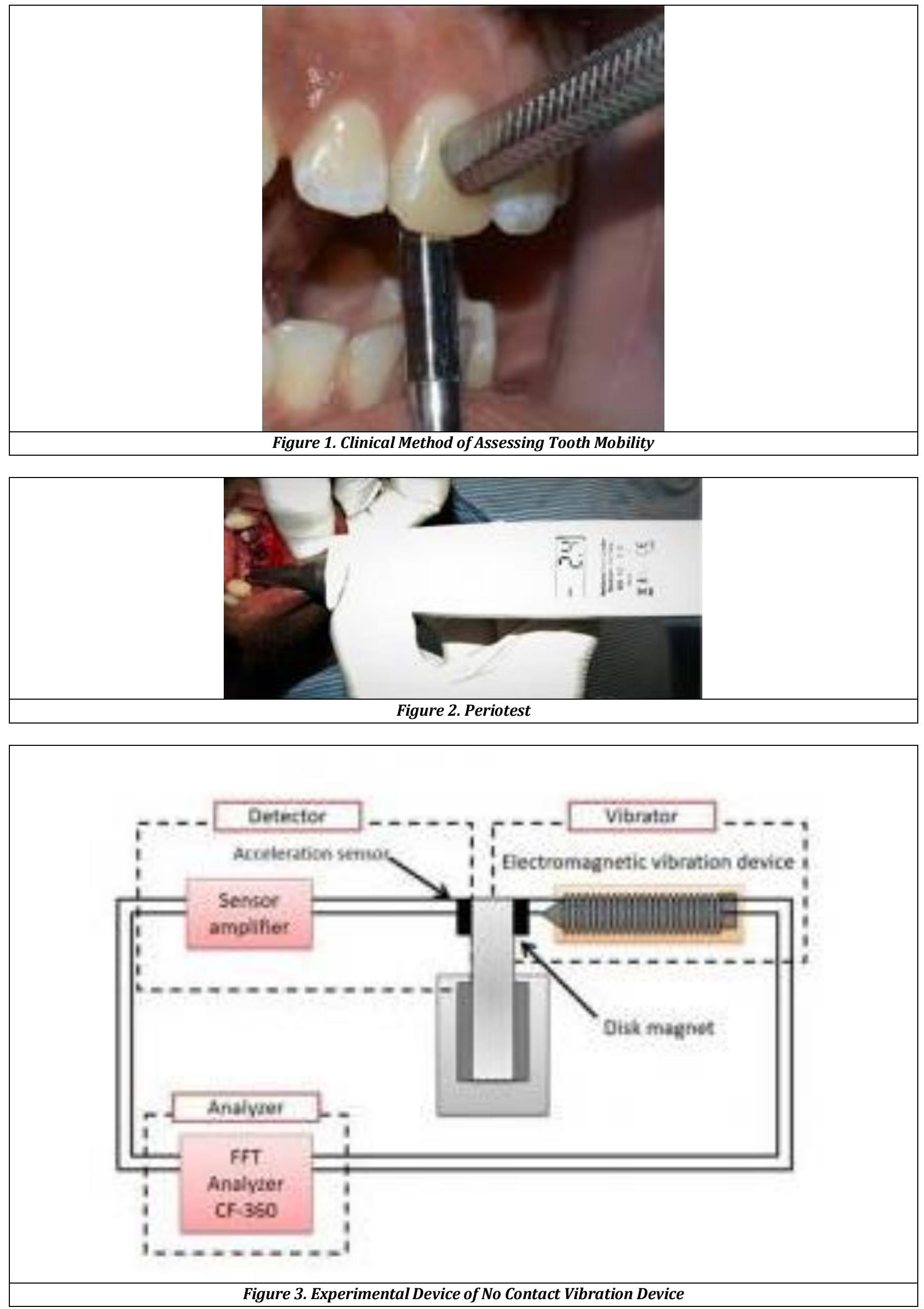


\begin{tabular}{|c|c|}
\hline 1. Miller (1938) & $\begin{array}{l}\text { Score } 0 \text { - No detectable movement when force is applied other than what is } \\
\text { considered normal (physiologic) } \\
\text { Score } 1 \text { - First distinguishable sign of movement } \\
\text { Score } 2 \text { - Mobility of } 1 \mathrm{~mm} \text { in a bucco-lingual direction } \\
\text { Score } 3 \text { - Movement of more than } 1 \mathrm{~mm} \text { in a bucco-lingual direction with ability } \\
\text { to depress the tooth } \\
\text { Its value for clinical research is limited by its inability to discriminate closely and } \\
\text { by its subjectivity }\end{array}$ \\
\hline 2. Lovdal (1959) & $\begin{array}{l}\text { First degree - teeth that are somewhat more mobile than normal } \\
\text { Second degree - teeth showing conspicuous mobility in the axial direction } \\
\text { Third degree - teeth being mobile in axial as well as in transversal direction } \\
\text { Utilizes fewer objective criteria than either of the previously mentioned methods }\end{array}$ \\
\hline Prichard's Index (1972) & $\begin{array}{l}\text { Slight mobility } \\
\text { Moderate mobility } \\
\text { Extensive movement in lateral and mesio-distal direction combined with vertical } \\
\text { displacement in the alveolus } \\
\text { Positive or negative sign can be used for added refinement } \\
\text { The system of grading depends on individual examiner. It cannot be copied } \\
\text { exactly but can be adequately adopted for clinical purposes }\end{array}$ \\
\hline 4. Wasserman et al. (1973) & $\begin{array}{l}\text { Normal } \\
\text { Slight mobility i.e. less than approx. } 3 / 4 \mathrm{~mm} \text { of bucco-lingual movement } \\
\text { Moderate mobility i.e. up to } 2 \mathrm{~mm} \text { of bucco-lingual movement } \\
\text { Severe mobility i.e. more than } 2 \mathrm{~mm} \text { of bucco-lingual movement } \\
\text { Index has a limitation that out of } 5 \text { possible scores three are reserved for highly } \\
\text { mobile teeth }\end{array}$ \\
\hline 5. Nyman (1975) & $\begin{array}{l}\text { Degree } 1 \text { - Horizontal or mesio-distal mobility of }<0.2 \mathrm{~mm} \\
\text { Degree } 2 \text { - Horizontal or mesio-distal mobility of } 0.2-1 \mathrm{~mm} \\
\text { Degree } 3 \text { - Horizontal or mesio-distal mobility exceeding } 2 \mathrm{~mm} \text { and/ or vertical } \\
\text { mobility }\end{array}$ \\
\hline 6. Laster \& Stoller (1975) & $\begin{array}{l}\text { Modified original Millers Index by adding scores of } 1 / 2,1 \frac{1}{2} \& 21 / 2 \text { to existing } \\
\text { Millers score of } 1,2 \& 3 \text { giving the clinicians a total of seven increments for } \\
\text { mobility. } \\
\text { The modified Millers index appeared to be highly accurate and clinically } \\
\text { acceptable method of assessing horizontal tooth mobility on an averaged basis }\end{array}$ \\
\hline 7. Glickman (1976) & $\begin{array}{l}\text { Normal } \\
\text { Grade } 1 \text { - Slightly more than normal } \\
\text { Grade } 2 \text { - Moderately more than normal } \\
\text { Grade } 3 \text { - Severe mobility facio-lingually and/ mesio-distally combined with } \\
\text { vertical displacement } \\
\text { It attempts to arrive at a diagnosis rather than to a parameter of the status of the } \\
\text { periodontium. }\end{array}$ \\
\hline 8. Fleszars' (1980) & $\begin{array}{l}\text { M0: Physiological mobility/ firm tooth } \\
\text { M1: Slightly increased mobility } \\
\text { M2: Definitive considerable increase in mobility but no impairment of function } \\
\text { M3: Extreme mobility, loose tooth that would be incompatible in function } \\
\text { Subjective nature of the tooth mobility measurements }\end{array}$ \\
\hline 9. Perlitsch (1980) & $\begin{array}{l}\text { Stage N: Normal with no radiographic evidence of bone loss } \\
\text { Stage 1: } 10-30 \% \text { loss of periodontal support } \\
\text { Stage 2: } 30-60 \% \text { loss of periodontal support } \\
\text { Stage 3: more than } 60 \% \text { loss of periodontal support }\end{array}$ \\
\hline $\begin{array}{l}\text { 10. O'Leary's stated normal values, } \\
\text { beyond, which is pathologic tooth } \\
\text { mobility (1974) }\end{array}$ & $\begin{array}{l}26-42 \times 10^{-4} \text { inch for incisors } \\
20-27 \times 10^{-4} \text { inch for premolars } \\
20-30 \times 10^{-4} \text { inch for molars }\end{array}$ \\
\hline $\begin{array}{l}\text { 11. Muhlemann's Index stated normal } \\
\text { values, beyond, which is pathologic, } \\
\text { tooth mobility }\end{array}$ & $\begin{array}{l}\mathrm{T}_{500}=15 \text { for single-rooted teeth } \\
\mathrm{T}_{500}=10 \text { for multi-rooted teeth } \\
\mathrm{T} \text { is here total transversal mobility in } 100^{\text {th }} \text { of } \mathrm{mm} \text { when the tooth is loaded with } \\
500 \text { ponds }\end{array}$ \\
\hline 12. Lindhe & $\begin{array}{l}\text { Degree-1 - slight mobility, movement of tooth by approximately } 0.2-1 \mathrm{~mm} \\
\text { Degree-2 - moderate mobility, movement in } \\
\text { horizontal direction, by } 1 \mathrm{~mm} \text {, but no evidence of } \\
\text { vertical movement } \\
\text { Degree } 3 \text { - Marked mobility }\end{array}$ \\
\hline 13. Schluger's classification & $\begin{array}{l}0 \text { - Clinical mobility within normal range } \\
(-) \text { - Clinical mobility considered slightly more than physiologic but less than } 1 \\
\text { mm bucco-lingual } \\
1 \text { - Clinical mobility approx. } 1 \mathrm{~mm} \text { bucco-lingually } \\
2 \text { - Clinical mobility approx. } 2 \mathrm{~mm} \text { bucco-lingually but no mobility in apical } \\
\text { direction }\end{array}$ \\
\hline
\end{tabular}




\begin{tabular}{|c|c|}
\hline & $\begin{array}{l}3 \text { - Clinical mobility greater than } 2 \mathrm{~mm} \text { bucco-lingually in addition to mobility in } \\
\text { apical direction }\end{array}$ \\
\hline 14. Ramjford & $\begin{array}{l}\text { M0 - Physiologic mobility, firm tooth } \\
\text { M1 - Slightly increased mobility } \\
\text { M2 - definite to considerable increase in mobility, but no impairment of function } \\
\text { M3 - Extreme mobility, a 'loose' tooth that would be uncomfortable in function }\end{array}$ \\
\hline 15. Loe & $\begin{array}{l}0 \text { - No mobility } \\
1 \text { - A mobility of } 1 \mathrm{~mm} \text { bucco-lingually } \\
2 \text { - A mobility of } 2 \mathrm{~mm} \text { bucco-lingually }\end{array}$ \\
\hline 16. Grant, Stern and Ernest & $\begin{array}{l}0 \text { - No perceptible movement } \\
1 / 2 \text { - barely perceptible movement of healthy lower incisor } \\
11 / 2-21 / 2 \text { - increased movement of teeth } \\
3 \text { - teeth can be depressed, hopeless prognosis } \\
\text { Does not utilize specific linear measurements }\end{array}$ \\
\hline 17. Jenkins and Allan & $\begin{array}{l}\text { Grade I - visible horizontal mobility upto } 1 \mathrm{~mm} \\
\text { Grade II - visible horizontal mobility between } 1-2 \mathrm{~mm} \\
\text { Grade III - visible horizontal mobility greater than } 2 \mathrm{~mm} \text { or rotation or vertical } \\
\text { mobility }\end{array}$ \\
\hline 18. Manson and Eley & $\begin{array}{l}\text { Grade I - just discernible, } 0.2-1 \mathrm{~mm} \text { in horizontal direction } \\
\text { Grade II - easily discernible and over } 1 \text { mm labio-lingual displacement } \\
\text { Grade III - well marked labio-lingual displacement mobility of tooth up and down } \\
\text { in an axial direction }\end{array}$ \\
\hline 19. Grace and Smales & $\begin{array}{l}\text { Grade } 0 \text { - indicates no apparent mobility } \\
\text { Grade } 1 \text { - assigned to a tooth in which mobility is perceptible, but less than } 1 \mathrm{~mm} \\
\text { bucco-lingually } \\
\text { Grade } 2 \text { - mobility is between } 1 \text { to } 2 \mathrm{~mm} \\
\text { Grade } 3 \text { - exceeds } 2 \text { mm bucco-lingually or vertically } \\
\text { Can be useful to track the amount of mobility in teeth over a period of time }\end{array}$ \\
\hline \multicolumn{2}{|r|}{ Table 1. Indices for Measurement of Tooth Mobility } \\
\hline
\end{tabular}

\section{CONCLUSIONS}

In spite of the availability of an array of tooth mobility measuring aids, presently no single method is totally accurate and reliable until it is updated regularly. A combined assessment with one or more techniques may prove to be a better guide. Future efforts are required to develop a device which is simple, effective and saves time during routine dental diagnostics.

\section{REFERENCES}

[1] Mühlemann HR. Tooth mobility: a review of clinical aspects and research findings. J Periodontol 1967;38(6):686-713.

[2] Nyman SR, Lang NP. Tooth mobility and the biological rationale for splinting teeth. Periodontol 2000 1994;4:15-22.

[3] Mühlemann HR. 10 years of tooth-mobility measurements. J Periodontol 1960;31(2):110-22.

[4] Manly RS, Yurkstas A, Reswick JB. An instrument for measuring tooth mobility. J Periodontol 1951;22(3):148-55.

[5] Anderegg CR, Metzler DG. Tooth mobility revisited. J Periodontol 2001;72(7):963-7.

[6] Wang HL, Burgett FC, Shyr Y, et al. The influence of molar furcation involvement and mobility on future clinical periodontal attachment loss. J Periodontol 1994;65(1):25-9.

[7] Wheeler TT, McArthur WP, Magnusson I, et al. Modeling the relationship between clinical, microbiological and immunologic parameters and alveolar bone levels in elderly population. J Periodontol 1994;65(1):68-78.
[8] Mühlemann HR, Savdir S, Rateitschak KH. Tooth mobility-its causes and significance. J Periodontol 1965;36:148-53.

[9] Glargia M, Lindhe J. Tooth mobility and periodontal disease. J Clin Periodontol 1997;24(11):785-95.

[10] Laster L, Laudenbach KW, Stoller NH. An evaluation of clinical tooth mobility measurements. J Periodontol 1975;46(10):603-7.

[11] Persson R, Svensson A. Assessment of tooth mobility using small loads. J Clin Periodontol 1980;7(4):259-75.

[12] Mühlemann HR. Tooth mobility: the measuring method. Initial and secondary tooth mobility. J Periodontol 1954;25(1):22-9.

[13] Mühlemann HR. Periodontometry, a method for measuring tooth mobility. Oral Surg Oral Med Oral Pathol 1951;4(10):1220-33.

[14] Pameijer CH, Stallard RE. A method for quantitative measurements of tooth mobility. J Periodontol 1973;44(6):339-46.

[15] Oleary T], Rudd KD. An instrument for measuring horizontal tooth mobility. AEROSPACE MEDICAL DIV BROOKS AFB TX, 1963; 1:249.

[16] Picton DC. A method of measuring physiological tooth movements in man. J Dent Res 1957;36:814.

[17] Parfitt GJ. Measurement of the physiological mobility of individual teeth in an axial direction. J Dent Res 1960;39:608-18.

[18] Joel AA. A new method for measuring tooth mobility. D Pract and D Record 1958;8:329-332.

[19] Goldberg HJV. New technique for measuring tooth mobility. J Dent Res 1961;40:641.

[20] Korber KH. Periodontal pulsation. J Periodontol 1970;41(7):382-90. 
[21] Korber KH. Electronic registration of tooth movements. Int Dent J 1971;21(4):466-77.

[22] Rydén H, Bjelkhagen H, Söder PÖ. The use of laser beams for measuring tooth mobility and tooth movements. J Periodontol 1975;46(7):421-5.

[23] Wedendal PR, Bjelkhagen HI. Dental holographic interferometry in-vivo utilizing a ruby laser system: I. Introduction and development of methods for precision measurements on the functional dynamics of human teeth and prosthodontic appliances. Acta Odontologica Scandinavica 1974;32(2):131-45.

[24] Kaneko T, Nagai Y, Ogino M, et al. Acoustoelectric technique for assessing the mechanical state of the dental implant-bone interface. J Biomed Mater Res A 1986;20(2):169-76.

[25] Schulte W, Lukas D. The periotest method. Int Dent J 1992;42(6):433-40.

[26] Meredith N, Cawley P, Alleyne D. The application of modal vibration analysis to study bone healing in-vivo. J Dent Res 1994;73:793.

[27] Meredith N, Alleyne D, Cawley P. Quantitative determination of the stability of the implant-tissue interface using resonance frequency analysis. Clin Oral Implants Res 1996;7(3):261-7.
[28] Castellini P, Scalise L, Tomasini EP. Teeth mobility measurement: a laser vibrometry approach. J Clin Laser Med Surg 1998;16(5):269-72.

[29] Wijaya SK, Oka H, Saratani K, et al. Development of implant movement checker for determining dental implant stability. Med Eng Phys 2004;26(6):513-22.

[30] Yamane M, Yamaoka M, Hayashi M, et al. Measuring tooth mobility with a no-contact vibration device. J Periodontal Res 2008;43(1):84-9.

[31] Berthold C, Auer FJ, Potapov S, et al. In vitro splint rigidity evaluation-comparison of a dynamic and a static measuring method. Dent Traumatol 2011;27(6):414-21.

[32] Konermann A, Al-Malat R, Skupin J, et al. In vivo determination of tooth mobility after fixed orthodontic appliance therapy with a novel intraoral measurement device. Clin Oral Investig 2017;21(4):1283-9.

[33] Kobayashi H, Yamaoka M, Hayashi M, et al. Use of a laser displacement sensor with a non-contact electromagnetic vibration device for assessment of simulated periodontal tissue conditions. J Oral Sci 2016;58(1):93-9. 